\title{
sciendo
}

\author{
GRZEGORZ ZIELIŃSKI, MICHAŁ BASZCZOWSKI, MICHAŁ GINSZT, ALEKSANDRA BYŚ, \\ PIOTR GAWDA
}

\section{The influence of the sensitivity of the trapezius muscle on the changes within the bioelectric tensions of the masticatory muscles}

\begin{abstract}
Introduction. Pathological muscle tone can cause changes in the facial skeleton, including tension headaches, tinnitus, temporomandibular joint dysfunctions. The complexity of pathologies and their spectrum may also indicate changes beyond the facial skeleton. The aim of the study was to determine the possible correlation between the pressure pain threshold of the trapezius muscle and the bioelectrical tension on the masticatory muscles.

Aim. The aim of the study was to determine the possible correlation between the pressure pain threshold of the trapezius muscle and the bioelectric tension on the masticatory muscles.

Material and methods. The number of 36 women applied for the study. They were all examined using an algometer within a trapezius muscle to determine the pressure pain threshold. The electromyographic study was carried out in accordance with the SENIAM guidelines. The resting activity of selected masticatory muscles (temporal and masseter) was recorded for 10 sec. The study involved an 8-channel BioEMG IIITM surface electromyography apparatus with BioPak Measurement System (BioResearch Associates, Inc. Milwaukee, WI, USA). Statistical analysis was carried out using the r-Pearson test. The level of significance was set at 5\%.

Results. After comparing the bioelectric tension of the masticatory muscles and the pressure pain threshold, left-sided correlation was observed $(\mathrm{p}<0.05)$. Both in the right-hand and general comparison, the results did not reach the required level of statistical significance $(\mathrm{p}>0.05)$.

Conclusions. The pressure pain threshold seems to be linked to the bioelectrical muscle tone of the masticatory muscles. To confirm this observation, further research into a larger and more diverse group of participants is recommended.
\end{abstract}

Keywords: sEMG, pressure pain threshold, trapezius muscle, TMD.

DOI: $10.2478 /$ pjph-2019-0012

\section{INTRODUCTION}

The pathological tension of the masticatory muscles can cause changes in the facial skeleton, leading to tension headaches, tinnitus and temporomandibular joint dysfunctions (TMD). Increased temporal muscle tension may affect the formation of tension-type headaches (TTH), whose mean global prevalence is $42 \%$ [1]. In addition, muscle imbalances in the region of masticatory muscles may lead to the development of tinnitus, which is explained by the common origin of phylogenetic structures of the temporomandibular joints and the ear [2]. Disorders in the asymmetry of muscle tone are also a predisposing factor for the occurrence of tempomandibular disorders (TMD). Their prevalence is estimated at 5 to $12 \%$ of the world's population, almost twice as much as women and men. The chronic form of TMD is associated with changes in masticatory muscle activity and can lead to sleep problems, deterioration of the emotional state and quality of life [3].

The complexity of pathologies and their spectrum may also indicate changes beyond the facial skeleton, which are combined by some authors with central sensitization. If we deal with a reduced local pain threshold, this may indicate an increased nociceptive sensitization in a given area. On the other hand, the increased sensitivity to pain occurring in non-damaged or nonsensitive sites may be due to increased excitability of the central nervous system [4]. Lower PPT values are associated with the occurrence of myofascial Trigger points ( $\mathrm{TrP})$, what is associated with the changes in physiology mentioned above $[5,6]$.

\section{AIM}

The aim of the study was to determine the possible correlation between the pressure pain threshold of the trapezius muscle and the bioelectric tension on the masticatory muscles.

\section{MATERIAL AND METHODS}

The research was carried out in accordance with the recommendations of the Declaration of Helsinki and with the consent of the Bioethical Commission of the Medical University of Lublin (KE-0254/73/2017). Participants were informed about the aim of the study, they were aware of the possibility 
of resignation at any time. All the surveyed women gave written permission for the above research.

The number of 36 women applied for the study. The following exclusion criteria were applied: neurological disorders, injuries and surgical procedures within the head and neck section of the spine and pregnancy. After applying the abovementioned criteria, 17 women were qualified for the study (mean age: 23 years \pm 2 years). All the women were examined using an algometer within the trapezius muscle (QM) to determine the pain threshold (PPT). The examination took place in a sitting position on the dental chair with legs extended, the hands were located along the trunk, the head was based on the headrest. The PPT value for both the left and the right trapezius muscle was determined using three measurements using a standard digital algometer (FDIX, Wagner Instruments, Greenwich), according to the methodology described by Moloney and Witney [7]. The average PPT value for each page was used for statistical analysis.

The electromyographic study was carried out in accordance with the guidelines of the SENIAM program [5]. Before placing the surface electrodes, the skin of the subjects was cleaned with $90 \%$ ethanol solution. Next, two surface electrodes $(\mathrm{Ag} / \mathrm{AgCl}$ with a diameter of $30 \mathrm{~mm}$ and a conductive surface of $16 \mathrm{~mm}$ - SORIMEX, Poland) were placed on one muscular flank, symmetrical on both sides, according to the course of the fibers of the frontal temporal muscle (TA) and the superficial part of the masseter muscle (MM). The reference electrode was placed on the forehead [8]. The study involved an 8-channel BioEMG IIITM surface electromyography apparatus with BioPak Measurement System (BioResearch Associates, Inc. Milwaukee, WI, USA). Before the test, an interference test was performed. Masticatory muscles' activity (TA, MM) was recorded in the resting position of the mandible for 10 seconds. Participants were instructed not to open their mouth during the study and not to swallow saliva. The eyes were closed during the examination.

The data was compiled using the IBM SPSS STATISTICS 21 program. Correlations were calculated using the r-Pearson test. The results were considered statistically significant if they exceeded the assumed level of statistical significance of 5\%.

\section{RESULTS}

After comparison of the bioelectrical tension of the masticatory muscles and the pressure pain threshold, left-sided correlation was observed $(\mathrm{p}<0.05)$ (Table 1), while in both righthand (Table 2) and general (Table 3), the results did not reach the required level of statistical significance $(\mathrm{p}>0.05)$.

TABLE 1. Comparison of the bioelectric tension of the masticatory muscles and the pressure pain threshold of the trapezius muscle on the left side.

\begin{tabular}{ccccc}
\hline \hline N & Age & $\begin{array}{c}\text { Pressure pain } \\
\text { threshold trapezius }\end{array}$ & $\begin{array}{c}\text { Bioelectric } \\
\text { tension }\end{array}$ & $\mathbf{P}$ \\
\hline 17 & $23 \pm 2$ & $4.35 \pm 1.25$ & $5.81 \pm 11.63$ & $\begin{array}{c}(\text { r-Pearsona }=0.536) \\
0.027\end{array}$ \\
\hline
\end{tabular}

TABLE 2. Comparison of the bioelectric tension of the masticatory muscles and the pressure pain threshold of the trapezius muscle on the right side.

\begin{tabular}{ccccc}
\hline \hline N & Age & $\begin{array}{c}\text { Pressure pain } \\
\text { threshold trapezius }\end{array}$ & $\begin{array}{c}\text { Bioelectric } \\
\text { tension }\end{array}$ & $\mathbf{P}$ \\
\hline 17 & $23 \pm 2$ & $4.86 \pm 1.20$ & $2.73 \pm 1.94$ & $\begin{array}{c}\text { (r-Pearsona }=-0.204) \\
0.432\end{array}$
\end{tabular}

TABLE 3. General comparison of the bioelectric tension of the masticatory muscles and the pressure pain threshold of the trapezius muscle on the right side.

\begin{tabular}{ccccc}
\hline \hline $\mathbf{N}$ & Age & $\begin{array}{c}\text { Pressure pain } \\
\text { threshold trapezius }\end{array}$ & $\begin{array}{c}\text { Bioelectric } \\
\text { tension }\end{array}$ & $\mathbf{P}$ \\
\hline 17 & $23 \pm 2$ & $4.60 \pm 1.18$ & $4.27 \pm 5.93$ & $\begin{array}{c}\text { (r-Pearsona }=0.462) \\
0.062\end{array}$ \\
\hline
\end{tabular}

\section{DISCUSSION}

The results of the author's research indicate a significant correlation between PPT and elevated muscle tone of the masticatory muscles on the left side. This phenomenon may be related to the close connection of masticatory muscles and neck muscles, which form a functional whole by maintaining the balance and stabilization of the head [9]. The lack of balance between these structures can lead to changes in the resting position of muscles and, as a result, to muscle hyperactivity [10].

All the issues discussed above may also be related to the phenomenon of central sensitization. In this phenomenon, pain sensations are not located in the actual place of dysfunction nor in the nerve affected by the pathological process, nor in a place supplied by another branch of this nerve, or by a different nerve. A frequent occurrence of pain transmission is the transfer of pain sensations from the neck muscles to the vicinity of TMJ. One of the concepts explaining this phenomenon is based on the theory of convergence. It talks about the possibility of a greater number of centripetal neurons connected to one higher-order neuron, which may be one of the many neurons reaching the synapse with a single neuron. The pyramid consisting of synaptic floors running all the way to the brainstem and cerebral cortex is, under conditions of prolonged impulse, getting heavier in the reading, resulting in pain being felt in places not affected by dysfunction [9]. This phenomenon can be confirmed by research carried out by Gawda et al. [11], in which it has been proven that by working at the trigger points present on the descending part of the trapezius muscle, we can reduce the pain in the temporomandibular joints. This may indicate the significance of the connection that occurs between the trapezius muscle and TMJ.

Assuming the validity of the convergence theory quoted above, the correlation between the compression algometria of the trapezius muscle and the occurrence of elevated masticatory muscle tension observed in our study may be related to the fact that the depressed PPT of a given muscle may be indicative of the occurrence of $\operatorname{TrP}$ in it.

In work of Chatchawan et al., in which the characteristics and distribution of myofascial trigger points in patients with chronic tension-type pains were found, a greater number of active TrPs and lower PPP levels of active TrPs in the areas of the head, neck and shoulder compared to the upper back area were discovered. In the conclusions, the authors note that lower PPTs of active TrPs around the head, neck and shoulder may affect chronic tension-type pain [6]. This is confirmation of the correlation discussed in the original study.

The next explanation of the obtained results may be related to the fascia that surrounds all the structures of the human body. It is a connection between all the components of the musculoskeletal system, which can cause the transfer of tension from the trapezius muscle to the area of the masticatory muscle [12]. The discussed relationship is explained by the work of Stecco, describing the sequences of the external rotation of the trunk. 
According to the author, the external rotation of the head is associated with tense temporal-parietal fascia and deep fascia of the skull in the distal direction, in which the splenius capitis muscles participate, while a further tension is transmitted along the entire posterior lateral part of the trunk [13]. A small group of people examined in the author's research could have only one-sided dysfunctions of the described sequence, which affected the occurrence of correlation only on the left side.

The relationship observed by us may be important in a better understanding of the transfer of tensions between the structures of the musculoskeletal system and the impact of TrP on myofascial changes, allowing for a global view and therapy of pain in the muscles of the masticatory system.

\section{CONCLUSIONS}

It seems that the pressure threshold of pain is associated with the bioelectrical incision of the masticatory muscle. To confirm this observation, further research into a larger and more diverse group of subjects is recommended.

\section{REFERENCES}

1. Ferrante T, Manzoni GC, Russo M, et al. Prevalence of tension-type headache in adult general population: the PACE study and review of the literature. Neurol Sci. 2013;34(Suppl. 1):137-8.

2. Zieliński G, Suwała M, Ginszt M, et. The relationship between masticatory muscles activity and tinnitus - preliminary study. Fam Med Primary Care Rev. 2019;21:66-9.

3. Zieliński G, Suwała M, Ginszt M, et al. Bioelectric activity of mastication muscles and the functional impairment risk groups concerning the masticatory muscles. Acta Bioeng Biomech. 2018;20(4):161-6.

4. King CD, Mano KEJ, Barnett KA, et al. Pressure pain threshold and anxiety in adolescent females with and without Juvenile Fibromyalgia: a pilot study. Clin J Pain. 2017;33:620-6.

5. Llamas-Ramos R, Pecos-Martín D, Gallego-Izquierdo T, et al. Comparison of the short-term outcomes between trigger point dry needling and trigger point manual therapy for the management of chronic mechanical neck pain: a randomized clinical trial. J Orthop Sports Phys Ther. 2014;44:852-61.

6. Chatchawan U, Thongbuang S, Yamauchi J. Characteristics and distributions of myofascial trigger points in individuals with chronic tension-type headaches. J Phys Ther Sci. 2019;31:306.

7. Moloney TM, Witney AG. Pressure pain thresholds increase after preconditioning $1 \mathrm{~Hz}$ repetitive transcranial magnetic stimulation with transcranial direct current stimulation. PLoS ONE. 2014;9:e92540.

8. Wieczorek A, Loster J, Loster B, et al. Correlation between activity and asymmetry indices and skeletal classes in symptomatic-free young adults. J Stomatol. 2013;66:750-60.

9. Okeson JP, Drobek W. Leczenie dysfunkcji narządu żucia i zaburzeń zwarcia. Lublin: Wydawnictwo Czelej; 2005.

10. Ritzel CH, Diefenthaeler F, Rodrigues AM, et al. Temporomandibular joint dysfunction and trapezius muscle fatigability. BJPT. 2007;11:333-9.

11. Gawda P, Michalik J, Ginszt M, et al. Assessment of the efficacy of trigger point therapy of the trapezius muscle using superficial electromyography in patients with temporomandibular joint pain. Orthod Forum. 2016;12:814.

12. Schleip R, Saulicz E, Findley TW, et al. Powięź: badanie, profilaktyka i terapia dysfunkcji sieci powięziowej. Wrocław: Edra Urban \& Partner; 2016.

13. Stecco L, Poncyljusz P, Stecco C. Manipulacja powięzi w zespołach bólowych układu ruchu: część praktyczna. Szczecin: Wydawnictwo Odnowa; 2015.

\section{Corresponding author}

Dr hab. Piotr Gawda

Chair and Department of Rehabilitation, Physiotherapy and Balneotherapy, Medical University of Lublin Aleje Racławickie 1, 20-059 Lublin

E-mail: piotr.gawda@umlub.pl 